Published in final edited form as:

Spine J. 2011 September ; 11(9): 816-823. doi:10.1016/j.spinee.2010.10.019.

\title{
Walking assessment in people with lumbar spinal stenosis: capacity, performance, and self-report measures
}

\author{
Justin Conway, BA ${ }^{*}$, Christy Tomkins, Ph.D.+, and Andrew J. Haig, M.D.* \\ ${ }^{*}$ The University of Michigan Department of Physical Medicine and Rehabilitation, Ann Arbor, MI \\ +Mount Royal University, Calgary, Canada
}

\section{Abstract}

Background context-Ambulation limitation is the hallmark of impairment in lumbar spinal stenosis (LSS). Capacity and performance have been defined as two distinct aspects of disability. Previous literature suggests that a person's walking capacity may not be reflected in their daily walking performance.

Purpose-To examine the relationship between survey instruments, tested walking capacity, and daily ambulatory performance in people diagnosed with LSS.

Design/Settings-Prospective laboratory and clinical observational study at a tertiary care spine clinic.

Patient Sample-12 subjects with LSS significant enough to be scheduled for epidural injection.

Outcome measures-Questionnaire (including the Swiss Spinal Stenosis Questionnaire, Pain Disability Index, Oswestry Disability Index, Quebec Back Pain Disability Scale, and SF-36), laboratory walk testing (walking capacity) and activity monitors (community ambulation).

Methods-Subjects filled out functional questionnaires; performed a Self-Paced Walking Test (SPWT) of up to 30 minutes; and wore an Actigraph activity monitor during waking hours for 7 days.

Results-There was no statistically significant relationship between walking capacity (SPWT) and community ambulation per day (activity monitors), however the maximum time of continuous activity during community ambulation had a strong relationship ( $\mathrm{r}=0.63)$ with the SPWT. Fifteen self-report measures of ambulation were significantly correlated with the SPWT, activity monitor, or both. Of these, $13(87 \%)$ were more highly correlated to the SPWT than the activity monitor. The SPWT test had a strong relationship $(r>.60, p<.05)$ with global function scales, but community ambulation did not.

Conclusions-Walking capacity and walking performance in LSS appear to be different constructs. Survey instruments appear to reflect capacity rather than performance. This dissociation between walking capacity and performance has implications for the clinical management and outcomes assessment of people with LSS.

(C) 2010 Elsevier Inc. All rights reserved.

Address correspondence to: Andrew J. Haig, M.D., Department of Physical Medicine and Rehabilitation, The University of Michigan, 325 E. Eisenhower, Ann Arbor, MI 48108, USA, andyhaig@umich.edu, 734-763-4200, fax 734-615-1770.

Publisher's Disclaimer: This is a PDF file of an unedited manuscript that has been accepted for publication. As a service to our customers we are providing this early version of the manuscript. The manuscript will undergo copyediting, typesetting, and review of the resulting proof before it is published in its final citable form. Please note that during the production process errors may be discovered which could affect the content, and all legal disclaimers that apply to the journal pertain. 


\section{Keywords}

Back pain; international classification of function; spinal stenosis; walking; functional capacity; participation; activity monitors

\section{Introduction}

One of the most fundamental measures of physical capacity and performance is ambulation. Walking is vital to many functions needed for everyday life. In addition, moderate physical activity has been shown to significantly reduce the risk of cardiovascular disease, thromboembolic stroke, and type 2 diabetes mellitus.1 Regular walking has also been shown to delay cognitive impairment in the elderly, 2 improve sleep, 3 and aid in the management of depression and anxiety disorders.4 It is clear that walking is critical to overall health, and thus limitation in everyday ambulation is a serious clinical indicator that needs to be monitored by patients and their doctors.

Walking limitations are a hallmark of lumbar spinal stenosis (LSS). Anatomically, LSS is characterized by a narrowing of the lumbar spinal canal or nerve root foramen. Clinically, people with LSS present with a variety of symptoms including back pain, neurological deficits and pain in the lower limbs.5; 6 The cardinal symptom of LSS is neurogenic claudication, described as leg pain and or numbness, weakness and tingling that is exacerbated by walking, standing and lumbar extension.7 Such symptoms of LSS often lead to substantial disability, 8 where activities requiring walking or prolonged standing are often avoided and health related quality of life is diminished. $9^{-} 11$

The discussion of disability related to LSS benefits from the common conceptual framework provided by the International Classification of Functioning, Disability and Health.12 One of the fundamental principles of the classification system is the difference between capacity (an individual's ability to perform a given task or action in a controlled setting) and performance (the activities performed by an individual on a day to day basis in the context of their own life). The distinction between capacity and performance is essential to the study of the ambulatory disability caused by LSS.

Because walking limitations play such a central role in LSS, the adequate assessment of ambulation-related disability is critical. The primary methods used to assess walking can be grouped into three major categories: 1) questionnaires to assess patients' perceived level of walking related disability,13-18 2) laboratory walking tests to determine ambulation capacity, $19^{-} 23$ and 3) community ambulation measured using activity monitors to assess walking performance in daily life. $24^{-} 26$ Traditionally, walking has been assessed in LSS populations using self report methods or objective tests of walking capacity in the laboratory setting. However, recent research has used activity monitors to measure daily physical activity of individuals from a variety of subject populations, including the elderly, stroke survivors, and cerebral palsy patients.18;27;28 The ability to measure duration and intensity of activity along with step counts has made activity monitors the gold standard in measuring physical activity for the purpose of medical research. $24^{-} 26$ Yet this method has received little attention in assessment of outcomes in LSS populations.

The purpose of the present study was to examine relationships between walking capacity and performance in people with LSS by comparing results of self-report questionnaires, a walking capacity test and activity monitoring of community ambulation. We hypothesized that self-reported walking disability would be more highly correlated with performance than with capacity. 


\section{Materials and Methods}

\section{Subjects}

This was a prospective laboratory and clinical observational study which took place at a tertiary care spine clinic. Possible subjects were identified through review of the clinic schedule for epidural injections at the University of Michigan Spine Program. All patients scheduled for epidural injection during a consecutive three month period who were identified as eligible for our study were called on the phone and provided information about our study.

Inclusion criteria were age over 45 years and a clinical diagnosis of LSS by either a physiatrist or a surgeon. Diagnosis was based on review of patient history, physical examination, and confirmation of anatomical stenosis on MRI. All subjects were required to have documented symptoms of neurogenic claudication (e.g. pain, numbness, weakness or tingling in the lower extremity brought on by lumbar extension, standing or walking). All subjects had been referred for epidural injection to treat lumbar spinal stenosis. Stenosis may have been at single or multiple levels. Exclusion criteria included disk herniation and/or other comorbidities that would limit walking capacity. Specific co-morbidities warranting exclusion included any other disorder that might be a limiting factor in ambulation. Examples include severe osteoarthritis of the hip or knee, peripheral vascular disease, coronary artery disease, and chronic obstructive pulmonary disease. All patients scheduled for epidural injection during consecutive three month period who were identified as eligible for our study were called on the phone and provided information about our study. Subjects agreeing to participate were scheduled for meeting with research staff the week prior to their injection and guided through the informed consent process. This project was granted approval by the Institutional Review Board IRBMed at the University of Michigan.

\section{Data Collection and Measures}

At the initial meeting, subjects filled out a questionnaire, completed a walking test and were then given an activity monitor and instructed to wear it for 7 days prior to their epidural injection.

Self-Report Measures-The questionnaire included demographic information, history of back/leg pain, walking specific questions, and five global function scales including: the Quebec Back Pain Disability Scale,29 Pain Disability Index,30 Oswestry Disability Index, 18 and the Physical Function and Symptom Severity subscales of the Swiss Spinal Stenosis Questionnaire (SSSQ).31 The walking specific questions were: "How would you say your walking capacity is today, on a scale of 0 to 10 , with 0 being your worst day, and 10 being your best day?", I can walk ___ feet without a rest before I MUST stop" and "When I am forced to stop walking I stop because of pain in my legs". These walking questions are meant to provide additional walking information which is not provided by the Swiss Spinal Stenosis Questionnaire and have been shown to be reliable and valid, using the Self Paced Walking Test as a criterion measure. 34

The Quebec Back Pain Disability Questionnaire (QBPDS) was used to assess pain and disability resulting from back pain. In the QBPDS, patients rate the degree of difficulty from 0 (not at all difficult) to 5 (unable to do) for performing 20 various activities, such as sleeping, standing for 20-30 minutes, and walking several miles. A total score is calculated by summing all 20 responses, with a higher score representing greater back pain related disability. Test-retest reliability for the English version is reported to be 0.93 , and internal consistency for the scale is 0.95 .29 
The Pain Disability Index (PDI) consists of 7 items used to measure a subject's perceived level of disability across various facets of life, including self-care, social activity, and family responsibilities. Severity of disability for each domain is rated on a $0-10$ visual analog scale, with a total maximum score of 70 points. A higher score represents higher pain related disability. Psychometric analysis of the PDI has supported its construct validity and reliability. 30

The 5-item Physical Function Scale of the Swiss Spinal Stenosis Questionnaire (SSSQ) is used primarily to assess walking capacity. The score was calculated as the un-weighted mean of the five items in the scale. The resulting possible scores of 1-4 represent a range from mild to severe limitation in physical function/walking.31 The 7-item Symptom Severity Scale of the SSSQ was included to examine severity of symptoms related to LSS, and is scored as the un-weighted mean of the seven items in the scale, with scores from 1-7 representing a range from mild to very severe pain. Both scales have been found to be internally consistent, reliable and responsive to clinical change. $15^{;} 31^{-} 34$

The Oswestry Disability Index (ODI) is a 9-item questionnaire which assesses degree of back pain-related disability. Severity of pain and disability in activities such as walking, sitting, standing and personal care are rated on Likert scales of 5 or 6 points. The ODI was calculated as a percentage of the total possible score of 53 , with a greater score representing greater back related disability.9;35 The ODI has repeatedly been shown to be a valid and reproducible measure of back-pain related disability and has been used specifically to evaluate walking in LSS populations.23;36

Overall health and disability was assessed using the 36 item Short Form Health Survey (SF-36).37 Each SF-36 question is categorized into one of the following scales: General Health, Physical Functioning, Social Functioning, Role Limitation - Physical, Role Limitation - Emotional, Mental Health, Energy/Fatigue, Pain, and Comparative Health. Each scale score is calculated independently using algorithms defined by the developers. 37

Walking Test and Clinical Measures-After completing the questionnaire, subjects completed a Self-Paced Walking Test (SPWT).33 In the SPWT, walking capacity is measured as the distance a person is able to walk continuously on a flat surface at a selfselected pace until being forced to stop due to symptoms of LSS, including neurogenic claudication (i.e. pain, numbness, tingling, or weakness in at least one leg or buttock) and/or low back pain, up to a limit of 30 minutes. If patients reported stopping due to reasons other than LSS symptoms (e.g. general fatigue, shortness of breath or dizziness), this was recorded and the walking test data was excluded from analysis. The SPWT was developed for use as a criterion measure of walking capacity in LSS patients and has been shown to have high retest reliability in this population.33 Subjects completed the SPWT along a flat hallway indoors or along the even surface of an outdoor parking lot. Time was kept using a stopwatch and distance was measured via a distance wheel (Stanley DMW40, New Britain, CT, USA) directly following the path of the subject. Immediately prior to and following the test, subjects completed $100 \mathrm{~mm}$ visual analog pain scales (VAS) for their back and legs as well as a body diagram describing the type and location of symptoms (pain, tingling, numbness, weakness) experienced at that time. During the SPWT, subjects were asked to alert the research staff when symptoms of LSS first began. The nature and location of these symptoms were recorded along with any other symptoms experienced during the test and the symptoms causing termination.

Activity Monitors-Upon completion of the walking tests, subjects were provided with an activity monitor (Actigraph GT1M, Actigraph LLC, Pensacola FL, USA) to wear for 7 days. Subjects were instructed to wear the activity monitors from the time they woke up in the 
morning to the time they went to bed at night for 7 days prior to their epidural injection. Activity monitors were worn on an elastic band around the waist at the level of the hip bone. Subjects were told to remove the monitor only while showering or swimming. Subjects were also instructed how to complete a daily activity log which was used in analysis to assess monitor data integrity. Activity monitors were collected by research staff at the time of the subject's epidural injection. The GT1M measures and records time varying accelerations 30 times per second to produce 'activity counts' and step counts over 60 second epochs. The activity score thresholds are defined based on algorithms developed by researchers specifically for the Actigraph and the counts are determined based on mathematical modeling programs within the Actigraph software. Anything less than or equal to an activity score of 100/minute is classified as sedentary. A score between 101/min to $1,952 / \mathrm{min}$ is defined as light intensity activity, with moderate intensity activity ranging from 1,953/min to $5,724 / \mathrm{min}$, and heavy intensity activity defined as an activity score $>5,725 / \mathrm{min} .38$ The Actigraph is widely accepted in the field as a valid and reliable means of assessing ambulatory physical activity. $39^{-} 44$

Data analysis-Pearson product moment correlation coefficients were used to examine the strength of relationships between variables. In the case of nominal or ordinal variables, Spearman correlation coefficients were used. A $p$ value of 0.05 was used to determine the significance of correlation. An $\mathrm{r}$ value of $>0.80$ was considered a very strong relationship, $0.60-0.79$ a strong relationship, $0.40-0.59$ a moderate relationship, and $<0.40$ a weak relationship. $45 ; 46$

For the activity monitor, a new variable was designed: maximum time of continuous activity. This was defined as the maximum number of continuous minutes per day at or above light intensity activity (activity score $>100$ /minute), with no more than one minute of activity below light intensity in between. The inclusion of bouts of activity with single minutes of no activity between is to allow for the normal stop and go nature of activity in one's life. This was decided upon because in our other work with LSS patients, in response to a question addressing the amount of time needed to recover after being forced to stop walking due to pain, the minimum time recorded was 2 minutes. Therefore we determined that allowing for a single minute of relative inactivity was acceptable and reflective of the functional demands of community activity.

\section{Results}

Each of the twelve recruited subjects completed all three phases of testing, including the self-report measures, SPWT, and activity monitor. Subject non-compliance, scheduling difficulties, and one case of an activity monitor that lost power prevented us from collecting the full 7 days of activity data on $7(58 \%)$ subjects. The minimum number of days of collected data was 4 days, with an average of $6.3 \pm 0.9$ days per subject. All subjects reported terminating the Self-Paced Walking Test due to symptoms of LSS (neurogenic claudication and/or low back pain), none were limited by other diseases..

Basic demographic and descriptive data for the subject population can be seen in Table 1. Of the total sample, $75 \%$ were male and the mean age was $66.3 \pm 9.8$ years. It should be noted that all but one of the subjects had a BMI in the overweight or obese range, with an average BMI of $33.4 \pm 7.8$. The majority of subjects $(83 \%)$ had either back or leg pain with rest, and $100 \%$ of subjects had both back and leg pain with walking. These symptoms are in keeping with the clinical diagnosis of LSS. Scores for the ODI and Physical Function Scale of the SSSQ are similar to those found in previous studies of walking in LSS.15;33;34 
The results from both the SPWT and activity monitor data can be seen in Table 2. Our data exhibits a wide range of both capacity and performance among our subject population. This reflects the variable nature of the impact of LSS on each individual. Table 3 illustrates correlations between the SPWT, activity monitor data, and self-report measures. A strong relationship $(\mathrm{r}=0.63, \mathrm{p}<.05)$ was observed between distance on the SPWT and maximum time of continuous activity per day as measured by the activity monitor $(\mathrm{r}=0.63)$. A moderate relationship was observed between the SPWT and overall activity per day $(\mathrm{r}=0.53)$, but this was not statistically significant $(\mathrm{p}=.078)$.

Fifteen self-report measures were found to have statistically significant correlations with the SPWT test, activity monitor (maximum time of continuous activity), or both. Of these 15 measures, 13 (87\%) were more highly correlated to the SPWT than the activity monitor. The SPWT test had a strong relationship $(r>.60, \mathrm{p}<.05)$ with the Quebec Back Pain Disability Scale, Swiss Spinal Stenosis Physical Function Survey, and Oswestry Disability Index, as well as the SF-36 Physical Functioning Scale, estimates of maximum distance without stopping, and weakness in the legs and feet.

The activity monitor data was significantly correlated with only two outcome measures. Walking limited by pain in the legs exhibited a strong relationship to both average activity per day $(r=0.623, p<.05)$ and maximum continuous activity per day $(r=0.754, p<.01)$. Both average activity per day and maximum continuous activity per day had a very strong relationship ( $\mathrm{r}=0.885$ and $\mathrm{r}=0.885$ respectively, $\mathrm{p}<.01$ ) with question \#12 on the QBPDS, in which subjects were asked to rate the difficult of running two blocks.

\section{Discussion}

This was the first study of its kind to examine the relationship between walking capacity and performance in people with LSS. A strong relationship was demonstrated between laboratory based walking capacity and maximum daily continuous activity measured with an activity monitor. A moderate, yet non-significant relationship was observed between walking capacity and average daily community ambulation. Questionnaires commonly used to evaluate walking in patients with LSS were shown to be mostly associated with capacity, not performance. This research also developed the activity monitor parameter of maximum continuous daily activity, which proved to be more highly correlated with walking capacity than any other measure of community-based activity.

The strengths of this study include the use of multiple, well-validated questionnaires to assess self-reported walking disability. The reliability of collected data was strengthened via use of the SPWT and the extended period of time (7 days) in which the subjects were instructed to wear the activity monitor. Limitations of this study include sample size, incomplete follow-up data, and non compliance. A lack of variation in gender and BMI among our study population may provide a degree of sampling error. Diagnostic criteria for stenosis, and thus inclusion criteria for this study, can be debated. The relationship between radiological stenosis and clinical symptoms has been seriously challenged by a number of studies.47 A recent study has shown important disagreement between expert surgeons as to the presence of neurogenic claudication among persons who have been offered surgery for spinal stenosis.48 However in keeping with current convention, a clinical diagnosis of LSS, including presence of neurogenic claudication, with anatomical stenosis confirmed on MRI, was used. Likely the population represented persons whom other reasonable clinicians would believe have spinal stenosis.

Participants in this study had lower average daily step counts than previous studies of older adults.25;49 Compared to research by Cavenaugh et al. 25 subjects in the current study had 
a markedly lower average daily step count (2821.9 steps/day) than both healthy older adults (9,981.7 steps/day) and older adults with 'functional limitations' (7,681.5 steps/day). This finding is a reminder of the severe compromise in life function imposed by clinical spinal stenosis.

This study provided new insight into the relationship between capacity and performance in LSS. Recent research by Zalewski et al.49 found that in residents of a critical care retirement community there was no relationship between performance on a clinic-based tests of walking capacity and community based walking performance. The results of the present study, however, did demonstrate a significant association between walking capacity and performance; Capacity to walk in the lab was observed to be significantly correlated with the average daily bout of maximum continuous activity in the community.

Though our results showed a correlation between walking capacity and performance in patients with LSS, our findings also suggest that walking capacity and performance are not the same, and as such should be treated as two separate entities. Maximum time of daily continuous activity appeared to be representative of walking capacity, but the more global measure of walking performance (average daily activity) was not significantly related to labbased walking capacity. This difference between capacity and performance appears to be of vital importance to the interpretation of questionnaires commonly used to assess the disability level of people with LSS. Our data shows that self-report measures used in this study are an indicator of capacity, not performance. Therefore, the data elicited by these questionnaires gives an incomplete, and possibly misleading, picture of a patient's level of disability.

This apparent discrepancy between walking capacity and performance has implications for both clinical practice and research related to treatment and assessment of mobility in LSS. The functional goal of interventions for LSS is thought to be improvement in performance, not capacity. A person who is made more capable of walking but does not take advantage of that capacity via increased performance will neither have an improvement in quality of life nor reap the well-documented benefits of walking participation on overall health.

Spinal stenosis is defined as an anatomical and physiological disorder. However, its impact on people's lives is multidimensional. As such, a single mode of treatment for LSS cannot be assumed to improve all facets of the disease. Treatments for LSS are commonly based on capacity; a treatment is deemed successful if the patient's ability to walk is improved. But if as mentioned, this improvement in capacity is not met with an improvement in performance (i.e. the actual walking done by the patient) then the patient's participation in daily activities and quality of life has gone unchanged. Thus, the treatment of patients performing under their capacity level will not result in a significant increase in daily activity levels unless the limiting factors to performance, whether they be physical, social, or psychological, are identified and subsequently addressed. A multidisciplinary assessment and perhaps multidisciplinary treatment of spinal stenosis patients may result in better outcomes.

In terms of research and outcomes assessment, this study shows that even a single function such as ambulation has many dimensions that cannot be measured using a single test or survey. If we are using outcome tools focusing on capacity (such as the SPWT or self-report tools), we may be missing the important impact or lack of impact on patients' day to day lives (performance). Activity monitors as used in the current study should be considered in future research with LSS patients, especially when trying to define the effects of interventions. Research into the nature of participation deficits and the factors (such as high BMI) that may lead to such deficits may result in interventions that are more specific to the actual problem of the patient. A larger database of ambulation profiles of persons with spinal 
stenosis will help us understand how capacity limitations affect participation and how people adapt to those limitations.

Finally, this data suggests that activity monitors may become useful in measurement of function in the clinical setting. It is possible that, in the future, the criteria for surgical intervention for spinal stenosis would include a drop in weekly activity below a certain level or a slope of decline that suggests that surgery is the better choice. A poor relationship between capacity and participation may alert the clinician that a multidisciplinary approach is needed.

\section{Conclusion}

There is a relationship between capacity to walk and actual performance in walking in the community, but it is not exact. Questions about ambulation on most standardized outcome tools appear to relate best to capacity, yet performance and participation are the more important life goals. This difference highlights the need for researchers to use tools such as activity monitors to measure participation as an ultimate outcome measure, and for clinicians to focus on the multifaceted barriers that exist between improved capacity and improved performance in daily life.

\section{Reference List}

1. Haskell WL, Lee IM, Pate RR, et al. Physical activity and public health: updated recommendation for adults from the American College of Sports Medicine and the American Heart Association. Circulation. 2007; 116:1081-1093. [PubMed: 17671237]

2. Abbott RD, White LR, Ross GW, et al. Walking and dementia in physically capable elderly men. JAMA. 2004; 292:1447-1453. [PubMed: 15383515]

3. King AC, Oman RF, Brassington GS, et al. Moderate-intensity exercise and self-rated quality of sleep in older adults. A randomized controlled trial. JAMA. 1997; 277:32-37. [PubMed: 8980207]

4. Brosse AL, Sheets ES, Lett HS, et al. Exercise and the treatment of clinical depression in adults: recent findings and future directions. Sports Med. 2002; 32:741-760. [PubMed: 12238939]

5. Chad DA. Lumbar spinal stenosis. Neurol.Clin. 2007; 25:407-418. [PubMed: 17445736]

6. Atlas SJ, Delitto A. Spinal stenosis: surgical versus nonsurgical treatment. Clin. Orthop.Relat Res. 2006; 443:198-207. 198-207. [PubMed: 16462443]

7. Porter RW. Spinal stenosis and neurogenic claudication. Spine. 1996; 21:2046-2052. [PubMed: 8883210]

8. Fanuele JC, Birkmeyer NJ, Abdu WA, et al. The impact of spinal problems on the health status of patients: have we underestimated the effect? Spine. 2000; 25:1509-1514. [PubMed: 10851099]

9. Iversen MD, Katz JN. Examination findings and self-reported walking capacity in patients with lumbar spinal stenosis. Phys.Ther. 2001; 81:1296-1306. [PubMed: 11444993]

10. Jonsson B, Annertz M, Sjoberg C, et al. A prospective and consecutive study of surgically treated lumbar spinal stenosis. Part I: Clinical features related to radiographic findings. Spine. 1997; 22:2932-2937. [PubMed: 9431629]

11. Jansson KA, Nemeth G, Granath F, et al. Health-related quality of life (EQ-5D) before and one year after surgery for lumbar spinal stenosis. J Bone Joint Surg.Br. 2009; 91:210-216. [PubMed: 19190056]

12. World Health Organization. Geneva: World Health Organization; 2001. International Classification of Functioning, Disability and Health: ICF. Ref Type: Report

13. Haro H, Maekawa S, Hamada Y. Prospective analysis of clinical evaluation and self-assessment by patients after decompression surgery for degenerative lumbar canal stenosis. Spine J. 2008; 8:380384. [PubMed: 17433781]

14. Weinstein JN, Lurie JD, Tosteson TD, et al. Surgical compared with nonoperative treatment for lumbar degenerative spondylolisthesis. four-year results in the Spine Patient Outcomes Research 
Trial (SPORT) randomized and observational cohorts. J Bone Joint Surg.Am. 2009; 91:12951304. [PubMed: 19487505]

15. Tomkins CC, Battie MC, Hu R. Construct validity of the physical function scale of the Swiss Spinal Stenosis Questionnaire for the measurement of walking capacity. Spine. 2007; 32:18961901. [PubMed: 17762299]

16. Yamashita K, Aono H, Yamasaki R. Clinical classification of patients with lumbar spinal stenosis based on their leg pain syndrome: its correlation with 2-year surgical outcome. Spine (Phila Pa 1976). 2007; 32:980-985. [PubMed: 17450073]

17. Tong HC, Haig AJ, Geisser ME, et al. Comparing pain severity and functional status of older adults without spinal symptoms, with lumbar spinal stenosis, and with axial low back pain. Gerontology. 2007; 53:111-115. [PubMed: 17095872]

18. De Vries SI, Van Hirtum HW, Bakker I, et al. Validity and reproducibility of motion sensors in youth: a systematic update. Med Sci Sports Exerc. 2009; 41:818-827. [PubMed: 19276851]

19. Deen HG Jr, Zimmerman RS, Lyons MK, et al. Test-retest reproducibility of the exercise treadmill examination in lumbar spinal stenosis. Mayo Clin.Proc. 2000; 75:1002-1007. [PubMed: 11040847]

20. Deen HG Jr, Zimmerman RS, Lyons MK, et al. Measurement of exercise tolerance on the treadmill in patients with symptomatic lumbar spinal stenosis: a useful indicator of functional status and surgical outcome. J Neurosurg. 1995; 83:27-30. [PubMed: 7782845]

21. Yamashita K, Hayashi J, Ohzono K, et al. Correlation of patient satisfaction with symptom severity and walking ability after surgical treatment for degenerative lumbar spinal stenosis. Spine. 2003; 28:2477-2481. [PubMed: 14595167]

22. Tenhula J, Lenke LG, Bridwell KH, et al. Prospective functional evaluation of the surgical treatment of neurogenic claudication in patients with lumbar spinal stenosis. J.Spinal Disord. 2000; 13:276-282. [PubMed: 10941885]

23. Gunzburg R, Keller TS, Szpalski M, et al. Clinical and psychofunctional measures of conservative decompression surgery for lumbar spinal stenosis: a prospective cohort study. Eur.Spine J. 2003; 12:197-204. [PubMed: 12709858]

24. Matthews CE, Chen KY, Freedson PS, et al. Amount of time spent in sedentary behaviors in the United States, 2003-2004. Am J Epidemiol. 2008; 167:875-881. [PubMed: 18303006]

25. Cavanaugh JT, Coleman KL, Gaines JM, et al. Using step activity monitoring to characterize ambulatory activity in community-dwelling older adults. J Am Geriatr.Soc. 2007; 55:120-124. [PubMed: 17233695]

26. Davis MG, Fox KR. Physical activity patterns assessed by accelerometry in older people. Eur J Appl Physiol. 2007; 100:581-589. [PubMed: 17063361]

27. Manns PJ, Tomczak CR, Jelani A, et al. Use of the continuous scale physical functional performance test in stroke survivors. Arch Phys.Med Rehabil. 2009; 90:488-493. [PubMed: 19254616]

28. de Bruin ED, Najafi B, Murer K, et al. Quantification of everyday motor function in a geriatric population. J Rehabil Res Dev. 2007; 44:417-428. [PubMed: 18247238]

29. Kopec JA, Esdaile JM, Abrahamowicz M, et al. The Quebec Back Pain Disability Scale. Measurement properties. Spine (Phila Pa. 1995 Feb 1.20:341-352. 1976;\%.

30. Tait RC, Chibnall JT, Krause S. The Pain Disability Index: psychometric properties. Pain. 1990; 40:171-182. [PubMed: 2308763]

31. Stucki G, Daltroy L, Liang MH, et al. Measurement properties of a self-administered outcome measure in lumbar spinal stenosis. Spine. 1996; 21:796-803. [PubMed: 8779009]

32. Stucki G, Liang MH, Fossel AH, et al. Relative responsiveness of condition-specific and generic health status measures in degenerative lumbar spinal stenosis. J.Clin.Epidemiol. 1995; 48:13691378. [PubMed: 7490600]

33. Tomkins CC, Battie MC, Rogers T, et al. A Criterion Measure of Walking Capacity in Lumbar Spinal Stenosis and its Comparison with a Treadmill Protocol. Spine. 2009; 34:2444-2449. [PubMed: 19829259]

34. Tomkins CC, Battie MC. Self-Report Measures of Walking in Lumbar Spinal Stenosis: Reproducibility and Validity. Spine. 2010 In Press. 
35. Katz JN, Lipson SJ, Chang LC, et al. Seven- to 10-year outcome of decompressive surgery for degenerative lumbar spinal stenosis. Spine. 1996; 21:92-98. [PubMed: 9122770]

36. Herno A, Airaksinen O, Saari T, et al. Computed tomography findings 4 years after surgical management of lumbar spinal stenosis. No correlation with clinical outcome. Spine. 1999; 24:2234-2239. [PubMed: 10562990]

37. Ware JE Jr, Sherbourne CD. The MOS 36-item short-form health survey (SF-36). I. Conceptual framework and item selection. Med Care. 1992; 30:473-483. [PubMed: 1593914]

38. Freedson PS, Melanson E, Sirard J. Calibration of the Computer Science and Applications, Inc. accelerometer. Medicine \& Science in Sports \& Exercise. 1998; 30(5):777-781. [PubMed: 9588623]

39. Rothney MP, Apker GA, Song Y, et al. Comparing the performance of three generations of ActiGraph accelerometers. J Appl Physiol. 2008; 105:1091-1097. [PubMed: 18635874]

40. Rothney MP, Schaefer EV, Neumann MM, et al. Validity of physical activity intensity predictions by ActiGraph, Actical, and RT3 accelerometers. Obesity.(Silver.Spring). 2008; 16:1946-1952. [PubMed: 18535553]

41. Corder K, Brage S, Ramachandran A, et al. Comparison of two Actigraph models for assessing free-living physical activity in Indian adolescents. J Sports Sci. 2007; 25:1607-1611. [PubMed: 17852668]

42. Corder K, Brage S, Ekelund U. Accelerometers and pedometers: methodology and clinical application. Curr.Opin.Clin.Nutr.Metab Care. 2007; 10:597-603. [PubMed: 17693743]

43. McClain JJ, Sisson SB, Tudor-Locke C. Actigraph accelerometer interinstrument reliability during free-living in adults. Med Sci Sports Exerc. 2007; 39:1509-1514. [PubMed: 17805082]

44. McClain JJ, Craig CL, Sisson SB, et al. Comparison of Lifecorder EX and ActiGraph accelerometers under free-living conditions. Appl Physiol Nutr.Metab. 2007; 32:753-761. [PubMed: 17622290]

45. Gross DP, Battie MC. Construct validity of a kinesiophysical functional capacity evaluation administered within a worker's compensation environment. J.Occup.Rehabil. 2003; 13:287-295. [PubMed: 14671992]

46. Innes E, Straker L. Validity of work-related assessments. Work. 1999; 13:125-152. [PubMed: 12441557]

47. Haig AJ, Tomkins C. Diagnosis and Treatment of Lumbar Spinal Stenosis. JAMA. 2010; 303(1): 71-72. [PubMed: 20051574]

48. Haig, AJ.; Park, P.; Henke, P.; Yamakawa, KSJ.; Valdivia, J.; Tomkins, C.; Loar, S. Accepted, Musculoskeltal Best Research Presentations. Seattle, WA: American Academy of Physical Medicine and Rehabilitation; 2010 November 4-7. The Reliability of the Clinical Diagnosis in Persons offered Surgery for Lumbar Spinal Stenosis.

49. Zalewski KR, Smith JC, Malzahn J, et al. Measures of physical ability are unrelated to objectively measured physical activity behavior in older adults residing in continuing care retirement communities. Arch Phys.Med Rehabil. 2009; 90:982-986. [PubMed: 19480874] 
Table 1

Subject demographics, clinical presentation, and self report measures $(n=12)$

\begin{tabular}{|c|c|c|c|c|}
\hline & All Subjects ( $n=12)$ & $\begin{array}{l}\text { Standard } \\
\text { deviation }\end{array}$ & Min & Max \\
\hline Age (years) & 66.25 & 9.8 & 53 & 81 \\
\hline Gender, \% Male & 75.0 & & & \\
\hline Body Mass Index (BMI) & 33.4 & 7.8 & 18.8 & 47.1 \\
\hline Duration of symptoms (years) & 4.7 & 1.5 & 1 & 10.8 \\
\hline Back pain at rest & $10(83.3 \%)$ & -- & & \\
\hline Back pain w/ walking & $12(100 \%)$ & -- & & \\
\hline Leg pain at rest & $10(83.3 \%)$ & -- & & \\
\hline Leg pain w/ walking & $12(100 \%)$ & -- & & \\
\hline VAS back, pre SPWT (mm) & 39.9 & 27.0 & 0 & 78 \\
\hline VAS back, post SPWT (mm) & 45.3 & 26 & 5 & 82 \\
\hline VAS pain leg, pre $\operatorname{SPWT}^{*}(\mathrm{~mm})$ & 30.1 & 23.2 & 0 & 62 \\
\hline VAS pain leg, post SPWT ${ }^{*}(\mathrm{~mm})$ & 51.8 & 26.9 & 9 & 87 \\
\hline Quebec & 48.2 & 16.8 & 21 & 74 \\
\hline PDI & 28.8 & 8.1 & 15.2 & 47 \\
\hline Swiss.PF & 2.51 & 0.38 & 2 & 3.2 \\
\hline Swiss.SS & 2.31 & 0.52 & 1.1 & 3 \\
\hline Oswestry (\%) & 48.9 & 11.6 & 28.3 & 69.8 \\
\hline \multicolumn{5}{|l|}{ SF-36: } \\
\hline General Health & 55.3 & 22.4 & 15 & 87 \\
\hline Physical Functioning & 25.8 & 19.9 & 5 & 60 \\
\hline Social Functioning & 52.1 & 19.8 & 25 & 75 \\
\hline Role Limited - Physical & 14.6 & 31.0 & 0 & 100 \\
\hline Role Limited - Emotional & 36.6 & 43.7 & 0 & 100 \\
\hline Mental Health & 59.3 & 23.3 & 4 & 84 \\
\hline Energy/Fatigue & 42.1 & 18.3 & 0 & 65 \\
\hline Pain & 30.3 & 16.4 & 0 & 62 \\
\hline Comparative Health & 56.3 & 21.7 & 25 & 100 \\
\hline Quality of Life ${ }^{* *}$ & 3.2 & 0.84 & 1 & 5 \\
\hline Overall health $^{* *}$ & 3.3 & 1.1 & 2 & 5 \\
\hline Life satisfaction ${ }^{* *}$ & 3.2 & 0.83 & 2 & 5 \\
\hline
\end{tabular}

Score of most painful leg was used

from SF-36

VAS $=$ Visual Analog Pain Scale

SPWT $=$ Self-Paced Walking Test

Quebec $=$ Quebec Back Pain Disability Scale

PDI = Pain Disability Index 
Swiss.PF $=$ Physical Function Scale of the Swiss Spinal Stenosis Questionnaire Swiss.SS = Symptom Severity Scale of the Swiss Spinal Stenosis Questionnaire Oswestry $=$ Oswestry Disability Index 
Table 2

Physical tests of capacity and performance $(n=12)$

\begin{tabular}{|r|c|c|c|c|}
\hline & Mean & Standard Deviation & Min & Max \\
\hline SPWT Distance (m) & 775.8 & 725.6 & 60 & 2065 \\
\hline SPWT Time (sec) & 840.4 & 690.2 & 67 & 1800 \\
\hline SPWT Distance to1 ${ }^{\text {st }}$ sx (m) & 202.5 & 296.1 & 10 & 900 \\
\hline Activity count/day (Actigraph activity count) & 99958.9 & 69224.7 & 21906 & 246249 \\
\hline Max cont activity (min) & 26.5 & 12.8 & 7.5 & 46.14 \\
\hline Steps/day & 2821.9 & 1996.8 & 790 & 6919 \\
\hline Meters walked/day & 1687.7 & 1447.0 & 371.3 & 4912.5 \\
\hline
\end{tabular}

SPWT $=$ Self-Paced Walking Test

SPWT Distance to ${ }^{\mathrm{St}_{\mathrm{SX}}}=$ Distance to the first onset of symptoms reported by the subject during the self-paced walking test 


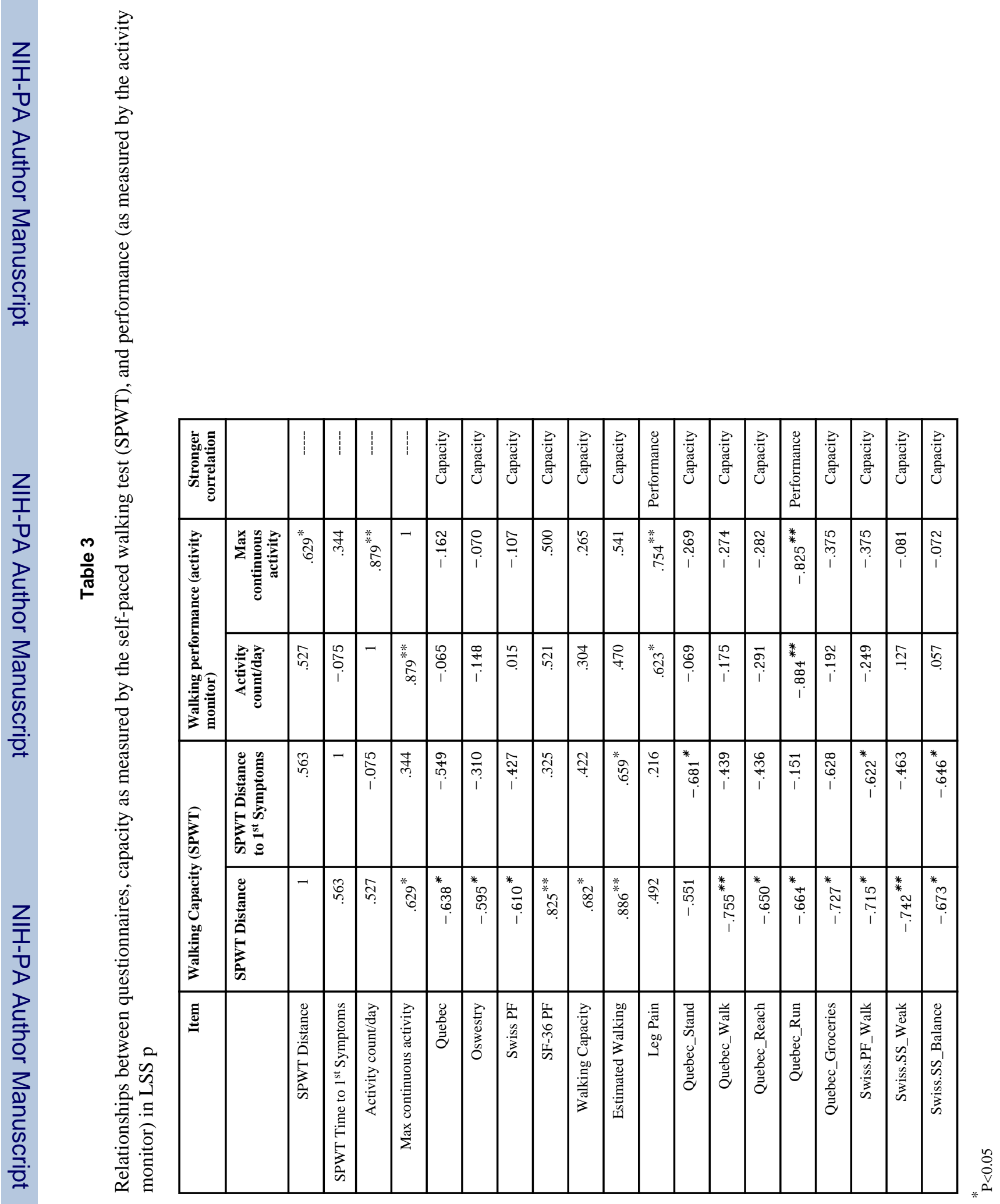




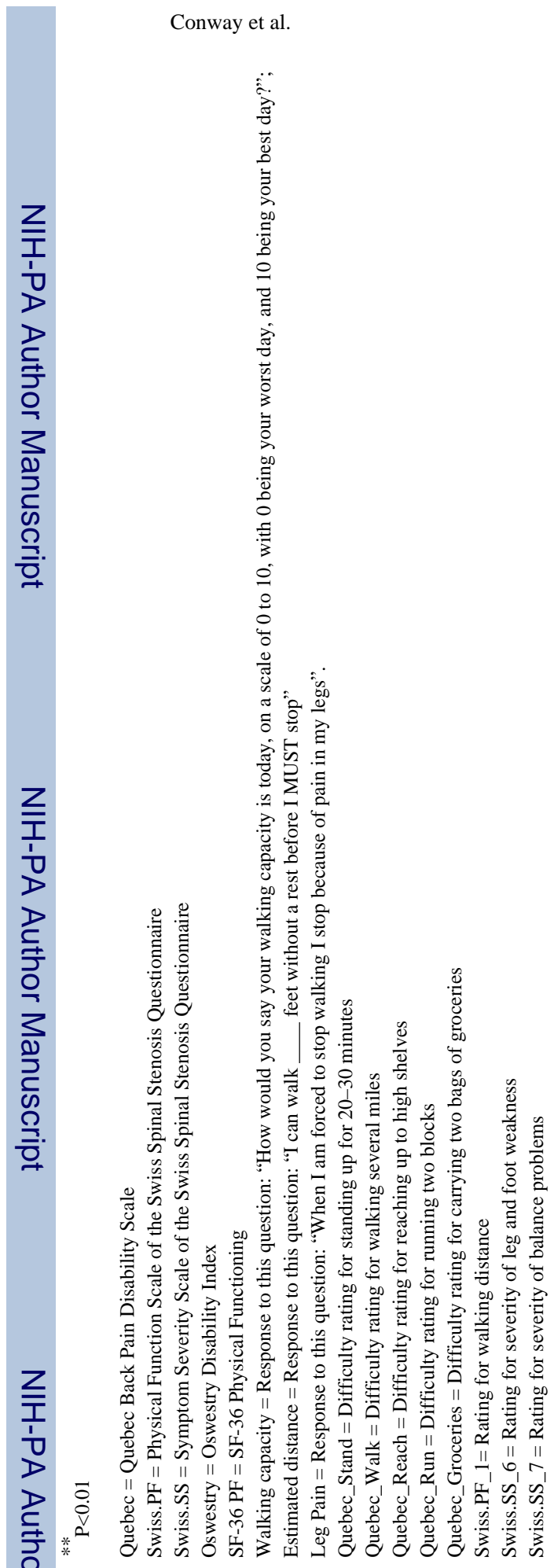

Page 15 